\title{
15
}

\section{Showing and not telling in a sign language}

\author{
John Haiman
}

Anna Wierzbicka's classic article on direct and indirect speech (1974) is one of the very few that I have read in linguistics whose major insight, once seen, can never again be unseen: direct speech (DS)—or at least that recycling of other speakers' words that is meant to be recognised as such-is a dramatic mimetic performance.

Direct speech (DS) is obviously an act of impersonation, in which a speaker identifies with and inhabits a character. Indirect speech (IS), on the other hand, is a distanced descriptive act whereby the speaker talks about the speech of others, as of all things other, from their own perspective, that is to say, from the outside. DS and IS therefore contrast exactly, as do vocal showing what's going on (e.g. shouting with anger/crooning with pleasure; paralanguage; ideophones) and telling a story about it (e.g. saying 'I am angry/ecstatic' or anything else in so many words; propositional language). Minimally contrasting utterances like, for example,

She said 'you're a liar'

She said (that) I was a liar

can thus be distinguished on the basis of simple syntactic tests. One of these is the 'go ...' or 'be, like ...' framing test in English. As is well known, these predicates introduce a dramatic performance: 
She goes

She's, like,

On the basis of this test, a dramatic performance may be any action (e.g. scratching one's ear), any posture (e.g. hunching over), any gesture (e.g. a shrug), any facial expression (e.g. a smile) or any ideophone (e.g. 'Yuk!'). It may also be any direct quote, but it can not be an indirect quote.

She goes/'s, like, 'You're a liar'

*She goes/'s like, that I was a liar

Comparable 'quotative frames' in other languages pick out the same roster of behaviours (cf. Güldemann 2008).

The present essay does not so much argue for the correctness of Anna's illuminating analysis (which strikes me as self-evident, now that she has pointed it out for all of us to see), as to point out another formal distinction between direct and indirect speech, this one in signed languages like ASL (American Sign Language), BSL (British Sign Language), German SL, Italian SL, Catalan SL and Quebec SL, which may be seen to follow naturally from this analysis. As such, it argues for the thesis that iconicity is unexpectedly the natural motivation for the expression of yet another conceptual distinction. And, via the circumstantial evidence afforded by this one example, it suggests, at least as an optimistic heuristic, that all signs (written, spoken or signed) may well derive from comparably natural beginnings. Laziness, convention and other factors may have rendered these iconic origins obscure over time.

One formal distinction in many if not all sign languages is this: in IS, signers maintain eye contact with their addressees, while in DS this eye contact is interrupted.

Since the scholars who originally described the phenomenon in ASL (Bellugi and Klima 1976: 521-22) and BSL (Sutton-Spence and Woll 1999: 95) provided no reason for this contrast, the distinction may seem to the outside observer to be yet another unremarkable example, among thousands, of the arbitrariness of the linguistic sign. Yet the coincidence among sign languages in this marking strategy argues that there must be some natural motivation behind it. (It should be noted that ASL and BSL, unlike American and British English, are totally distinct languages, as unlikely to trace their commonalities to common origin as Arabic and Hungarian.) Indeed, Quer (2005) and Jarque and Pascual (2015) report 
that the 'temporal interruption of eye contact with the interlocutor in the here and now', which they describe for DS in Catalan SL, is 'typical' in a variety of signed languages (Jarque and Pascual 2015: 429).

Suspension of eye contact is in fact only the tip of an iceberg of concomitant non-manual 'role shift' markers (Padden 1986) that signal DS. The others include change of head position, body shift and facial expression, with eye gaze change being the most frequent, most probably because it is the most compatible with the principle of least effort (Hermann and Steinbach 2012: 13; Hübl 2012).

The transparent, natural (and indeed to signers presumably self-evident) motivation for the marking of DS is immediately manifest once one correctly models the difference between Jakobson's (1965) 'Speech Stage', which is inhabited by the participants of the speech act (the speaker and the interlocutor right here and right now) and the 'Event Stage', which is inhabited by the signs they make: models of the things and events that they are talking about. It may seem from Jakobson's nomenclature that the Speech Stage (with its two inhabitants) is therefore infinitesimally small compared to the Event Stage, which may encompass the entire universe at any time; but the truth is the opposite. Consider the relationship between the two in Douglas Adams' immortal, but grammatically unexceptionable, sentence: 'Thus, the universe ended.' (Adams 1981: 146). (Spoken when, by whom, standing where?) As in the Adams example (1981), the participants of the speech act (in this case, Adams and his readers) are a part of the real world, but the Event Stage, rather than being the real world, for all its apparent size, is not 'the universe' but only a picture of it: it is merely a theatre in which they stage their linguistic productions. Not only is the Event Stage totally contained within the Speech Stage, those puppets that speakers animate are as remote from the real world inhabited by the speaker and the interlocutor as the characters of a play are supposed to be from the playwright and from their audience. As countless adages and proverbial expressions in a number of traditions make clear, all stages, like all games, are temporary bubbles of pretence, and what transpires on any stage is ideally distinct from what goes on in the real world. Thus, 'It's only a game', 'The show must go on', the notorious polysemy of the word 'play' in English and other languages for both games and dramatic representations (noted by Huizinga 1955), etc. 
That the bubble may in fact be punctured is well known. There are hybrid performances that are partially acts of showing and acts of telling: exhibitions of divided empathy with the characters on stage on the part of the impresarios (as in free indirect discourse), and self-referential 'postmodern' hijinks where the characters 'step off the stage' and directly address and thereby recognise the presence of their audience-also known as mugging. For all the hipness of these playful tweaks, it is notable that the bubble has some integrity: the distinction between showing and telling is a real one that is recurrently enforced by grammatical rules. Thus, in language after language, ideophones (dramatic performances on the Event Stage) cannot be negated (negation being a metalinguistic judgement expounded from the Speech Stage) (cf. Haiman 2018: 126).

The simplest model that diagrammatically characterises this contrast is one of two concentric circles. The innermost - the Event Stage, which I am calling a theatrical bubble-is admittedly a small part of the real world, like all theatres (Goffman 1974), but through the willing suspension of disbelief, separated from the real world for the duration of the performance. The outermost or Speech Stage, for all that it seems to contain only the speaker and the listener, is the one whose limits are actually coextensive with those of the real world. The formally heterogeneous class of shifters or egocentric particulars (among them the personal pronouns and tense, as well as the conventional deictics of time and place, but also a whole slew of apparently ordinary words like '(un)natural', 'foreign', 'familiar' and, arguably, most others) serve as anchors to situate the Event Stage and its participants and props with respect to the Speech Stage and the rest of the real world outside.

The extreme thesis that all words ultimately depend for their meanings on who is saying them and to whom, and thus serve as such shifty anchors, is proverbial; for example, one of these words, 'beauty', is exclusively in the eye and ear of the beholder. The same point is worked out in a fable by Ivan Krylov (1848) about a noted preacher whose spellbinding eloquence leaves one of his listeners completely unmoved, because he hails from a different parish. That truth is in the mouth of the speaker is notoriously asserted by Jorge Luis Borges in his 'Pierre Menard, author of the Quixote'. He argues, with a concrete demonstration, that the exact same words written by the historical Miguel Cervantes, a Spaniard of the seventeenth century, and his 'Pierre Menard', a fictional French symbolist poet of the twentieth century, mean radically different things. A random 
sentence of what is mere verbal wallpaper in Cervantes, writing in the seventeenth century, becomes radically, 'brazenly pragmatic' issuing from the pen of Pierre Menard (Borges 1941).

Consider now the position of the participants of the speech act, who can be thought of as the real-world impresarios on the Speech Stage who put on the make-believe show that proceeds on the Event Stage. They are not themselves a part of the show. They and the Speech Stage that they inhabit are equally part of the real world: as far as that communal participation goes, interlocutors relate as equals to each other. They recognise each other and give each other attention; they are equally 'above the fray'. But when as mimes/impersonators they 'step into character' in the Event Stage, they leave the real world behind. For the duration of their mimicry, the play's the thing and during their display they relate only to the other puppets on the Event Stage that they have created. This means that they do not recognise or relate to their real-life interlocutors when on stage, any more than do the characters portrayed by actors to the members of their audience. As eavesdropping inhabitants of the real world, we can see them, but they are not supposed to see us, or to be addressing us.

How can speech act participants in a gestured medium most naturally signal when they are above the fray (telling their story, talking about stuff from outside) or when they go native (acting it out)? A most natural performance of these two contrasting modes of discourse is for the signer to maintain eye contact in narrative/telling mode (explicitly signalling that 'I am talking to you'), and drop eye contact in dramatic/showing mode (leaving it to be inferred that 'I am not talking to you').

Accordingly, the absence of eye contact is also a distinctive feature of all pantomimed 'constructed action' (Quinto-Pozos 2006; Lillo-Martin 2012), where the signer as mime largely abandons conventional sign language and 'becomes one with'-and thereby shows, rather than tells-what s/he depicts. Maintaining eye contact, as in the use of conventional sign language, is how one signals that $\mathrm{s} /$ he remains above the fray, which is what $\mathrm{s} /$ he does when engaged in acts of telling. Not surprisingly the same distinction is used to signal the difference between direct and indirect speech.

As Capirci notes (pers. comm.) apropos of Italian SL:

The signer of DS takes the look of the character who speaks, so $s /$ he usually does not look at the actual interlocutor, but in the direction of the locutor within the [staged] narration. 
This is also the matter of fact observation of Hübl (2012:7) regarding German SL:

Non-manual markers reflect iconically the matrix signer's adoption of the role of the reported signer and his/her alignment towards the reported addressee.

Nothing could be more natural. As Dwight Bolinger sensibly observed (1975), there is probably nothing in language that is arbitrary simply because its original creators wanted it to be that way. In this case, we can see the iconicity behind apparent arbitrariness not, as we often can, by undoing the work of convention and abbreviation, but by identifying the appropriate model in terms of which signers conceive of direct and indirect speech. That natural model, as all signers and students of signed languages seem to recognise, and as Anna Wierzbicka taught the rest of us 45 years ago, is the iconic metaphor of the stage.

What is remarkable about this insight is how hard-won it is to workers in one tradition (spoken language theoreticians like me), but how selfevident it is to workers in another (sign language researchers). In a way my own recognition of this commonplace recapitulates an observation I once made about the metalinguistics of ordinary language, with particular reference to the stage model I have presented here, wherein the Speech Stage surrounds and encloses the Event Stage. The ontology of this diagram is explicit in the philology of the word 'about' in a number of spoken languages including English (Haiman 1998), and in at least one signed language, ASL, where 'about' is rendered by:

The left hand is held at chest height, all fingers extended and touching the thumb, and all pointing to the right. The right index finger circles about the left fingers several times. (Sternberg 1994: 1; emphasis added)

Language is everywhere more or less arbitrary, but it was probably born iconic. In fact, all human languages may have been born from what is now regarded by grammarians, if it is considered by them at all, as paralanguage (Fonagy 2002; Haiman 2018): unsystematic, largely idiosyncratic, analogue displays or performances that now linger in the spoken language as accompaniments to the digitally coded message, and in the written language not at all. 
Perhaps even now paralanguage is not quite so facultative as it is made out to be. Some authors (Nugent 2008) have suggested that the failure to attend to the paralanguage of others or to produce the required paralanguage oneself can be socially crippling, and is even a defining property of people with Asperger's syndrome, a population that, he argues, overlaps with canonical nerds.

Of course, making a distinction between language and paralanguage in signed languages is very much an unresolved issue, as is the distinction between language and gesture. I have myself suggested that gestures are those portions of the signal that are performed/shown rather than narrated/told (Haiman 2018: chapter 1). I have seen no discussion on whether 'constructed action' counts as language or paralanguage, for example, and I am unsure whether sign language theoreticians even consider the distinction a useful one. Sherman Wilcox (pers. comm.) suggests a convenient test for determining whether pantomimed 'constructed action' in signed languages is linguistic or paralinguistic: if it is linguistic, then fluent signers can identify as 'ungrammatical performances' those that they judge to be made by non-signers, while 'grammatical performances' are those that are attributed to native signers. If, however, fluent signers accept as equally grammatical all constructed action performances, whether they are produced by native signers or not, then constructed action will count as paralinguistic.

No present definition of paralanguage is entirely acceptable. One possible candidate might be the following one: what counts as paralanguage is always definable relative to an institutional code. Given such a code, paralanguage in any medium is those spontaneous dramatic performances (that is, gestures, by my definition) which co-occur with the coded signs of a message, but are so disinherited in that code that they cannot occur by themselves. They survive only as accompaniments to the coded linguistic signal. Matters are different when communicators share no common code: then paralanguage comes into its own as the only medium they've got.

Another possible definition, suggested by Wilcox's idea about grammaticality judgements of constructed action, is this: if a signal is universal (made with equal fluency and authority by both native speakers/signers and others), then it's probably motivated, and ipso facto paralinguistic. If, on the other hand, it's parochial, and properly produced only by native speakers/signers, then it is part of the grammatical code where it occurs. (I am cheerfully ignoring the ostensible charter of the 
whole 'generative enterprise', which is to assert hardwired externally unmotivated grammatical universals.) For example, in a small number of languages, interrogation is signalled by subject-verb inversion. This is a highly parochial fact, and part of the grammatical code wherever it happens. In many, if not most languages, interrogation is signalled by a rising intonation. This should count as paralinguistic signal, one that is so natural that it doesn't warrant a grammatical description. It becomes a grammatical fact if rising intonation is conventionalised in different ways in different languages. Thus, for example, Javanese is one of the many languages in which interrogativity can be signalled by rising intonation (as well as by conventional lexemes). But rising intonation in Javanese is not the same as rising intonation in English:

Normally, Javanese questions have intonation like the risingfalling pattern [characteristic of statements], except that the pitch does not fall so low at the end as for statements; it ends on a suspended note, as in the ' $\mathrm{B}$ ' speech of this sort of context:

[A. I like rainy weather.]

B. Well, I don't! (Horne 1961: xxvi)

Now it seems that the perfectly natural means of signalling DS that I have been describing is shared by several sign languages, and is naturally motivated. But if it is not shared by all of them, then, however natural its motivation may be, it becomes a parochial fact. So, if there is even one sign language in which gaze direction shift is not (or, possibly, cannot be) used to signal the shift into DS, then such gaze shift becomes part of the grammar, and no longer a paralinguistic natural accompaniment to the message, in those sign languages where it is so employed.

One final observation. To the extent that the degree of arbitrariness, indeed of the very systematicity, of a sign system is a consequence of conventionalisation over time, we may 'predict' a couple of present truisms: that the signs of written language, with its relatively shallow history, are more transparently or reconstructably iconic than those of spoken language (consult any history of writing), and that those of signed languages are more iconic than those of written ones (although the early history of signed language studies is replete with well-intentioned but (surely!) grotesque attempts by their promoters to assert that signed languages like ASL are by God as arbitrary-hence as worthy of respectas spoken languages). And we may well make a 'prediction' about the 
future: that signed languages will continue to grow ever more arbitrary as they become canonically sanctioned through repetition by established communities of the deaf. This prediction is already borne out by the existence of separate grammars for the various signed languages that have been described.

\section{Acknowledgements}

My thanks to Sherman Wilcox and Pamela Perniss for introducing me to the ideas of constructed action and role shift in sign languages. Thanks to Pamela also for answering my questions about German SL, and directing me to the wealth of literature on the topic. I am very grateful also to Paola Pietrandrea and Olga Capirci for answering my questions about Italian SL.

Anna Wierzbicka and I were colleagues at ANU for a few years more than 40 years ago and we had some great arguments. They were fun and I still miss them, although I never won any of them.

\section{References}

Adams, Douglas (1981). The Restaurant at the End of the Universe. New York: Ballantine Books.

Bellugi, Ursula and D. Klima (1976). The two faces of the sign. Special issue, Stevan Harnad, Horst D. Steklis and Jane Lancaster (eds), 'Origins and evolution of language and speech'. Annals of the New York Academy of Sciences 280 (1): 514-38. doi.org/10.1111/j.1749-6632.1976.tb25514.x.

Bolinger, Dwight (1975). Aspects of Language (2nd edn). New York: Harcourt Brace Jovanovich.

Borges, Jorge Luis (1941). Pierre Menard, autor del Quixote [Pierre Menard, author of the Quixote]. In Jorge Luis Borges, Ficciones [Fictions]. Madrid: Alianza Editorial, 47-60.

Fonagy, Ivan (2002). The Languages Within Language: An Evolutive Approach. The Hague: De Gruyter Mouton.

Goffman, Erving (1974). Frame Analysis. Chicago: Northwestern University Press. 
Güldemann, Tom (2008). Quotative Expressions in African Languages. Berlin: Mouton de Gruyter.

Haiman, John (1998). The metalinguistics of ordinary language. Evolution of Communication 2 (1): 117-35.

Haiman, John (2018). Ideophones and the Evolution of Language. Cambridge: Cambridge University Press.

Hermann, Annika and Markus Steinbach (2012). Quotation in sign languages: A visible context shift. In Isabelle Buchstaller and Ingrid van Alphen (eds), Quotations: Cross-linguistic and Cross-disciplinary Perspectives. Amsterdam: John Benjamins, 203-28. doi.org/10.1075/celcr.15.12her.

Horne, Elinor (1961). Beginning Javanese. New Haven: Yale University Press.

Hübl, Annika (2012). Role shift, indexicals and beyond: New evidence from German SL. Texas Linguistics Forum 13: 1-11.

Huizinga, Johan (1955). Homo Ludens. Boston: Beacon.

Jakobson, Roman (1965). Shifters, Verbal Categories, and the Russian Verb. Cambridge, MA: Harvard University Department of Slavic Languages and Literatures.

Jarque, Maria Josep and Esther Pascual (2015). Direct discourse expressing evidential values in Catalan Sign Language. Available at: www.semanticscholar. org/paper/Direct-discourse-expressing-evidential-values-in-Jarque-Pascual/ dd7fd16a6be11e9ec1d3486a6bfc30446b33503b.

Krylov, I.A. (1848 [1963]). Prixozhanin [The parishioner]. In Basni [Fables]. Moskva: Izdatel'stvo Xudozhestvennoj Literatury.

Lillo-Martin, Diane (2012). Utterance reports and constructed action. In Markus Steinbach, Roland Pfau and Bencie Woll (eds), Sign Language: An International Handbook. Berlin: Mouton de Gruyter, 365-87. doi.org/10.1515/9783110 261325.365 .

Nugent, Benjamin (2008). American Nerd. New York: Scribner.

Padden, C. (1986). Verbs and role shifting in ASL. In C. Padden (ed.), Proceedings of the Fourth National Symposium on Sign Language Research and Teaching. Silver Spring, Maryland: National Association of the Deaf, 44-57.

Quer, Josep (2005). Context shift and indexical variation in sign languages. In Efthymia Georgala and Jonathan Howell (eds), Proceedings of Semantics and Linguistic Theory XV. Ithaca: Cornell University, 152-68. doi.org/10.3765/salt. v15i0.2923. 
Quinto-Pozos, David (2006). Can constructed action be considered obligatory? Lingua 117: 1285-314. doi.org/10.1016/j.lingua.2005.12.003.

Sternberg, Martin (1994). American Sign Language Concise Dictionary. New York: Harper.

Sutton-Spence, Rachel and Bernice Woll (1999). The Linguistics of BSL: An Introduction. Cambridge: Cambridge University Press.

Wierzbicka, Anna (1974). The semantics of direct and indirect discourse. Papers in Linguistics 7 (3): 267-307. doi.org/10.1080/08351817409370375. 
This text is taken from Meaning, Life and Culture: In conversation with Anna Wierzbicka, edited by Helen Bromhead and Zhengdao Ye, published 2020 by ANU Press, The Australian National University,

Canberra, Australia.

doi.org/10.22459/MLC.2020.15 